\section{A Hybrid of Buddleja davidii var. nanhoensis 'Nanho Purple' and B. lindleyana}

\author{
W. Elliott' ${ }^{1}$ D.J. Werner ${ }^{2}$ and P.R. Fantz ${ }^{2}$ \\ Department of Horticultural Science, North Carolina State University, Box \\ 7609, Raleigh, NC 27695-7609
}

Additional index words. Buddleja davidii, Buddleja lindleyana, butterfly bush, Buddlejaceae, Loganiaceae, Scrophulariaceae, breeding, hybrids, RAPD analysis

Abstract. A controlled cross between Buddleja davidii var. nanhoensis (Chitt.) Rehd. 'Nanho Purple' and B. lindleyana Fort. ex Lindl. produced a hybrid. Pollen viability, male fertility, and the floral and vegetative characters are presented with a Latin diagnosis. Buddleja $\mathrm{x}$ luteolufaucia Elliott and Fantz is proposed as the name for this hybrid. Hybridity was confirmed using RAPD analysis.

Buddleja L. (orthogr. syn. Buddleia) consists of $\approx 100$ species (Griffiths, 1994). The genus has been placed in several families including Scrophulariaceae Juss. (Rogers, 1986) and Loganiaceae Mart. (Griffiths, 1994) as well as its own family Buddlejaceae K. Wilh. (Bhattacharyya and Johri, 1998). Most species are tropical or subtropical shrubs originating in Asia, South Africa, and North and South America. Buddleja has a number of qualities that make it a desirable ornamental shrub. Plants exhibit extended flowering periods and produce long panicles of flowers that attract butterflies and bees. Buddleja are widely adaptable, tolerating poor soil, heat and drought, and suffer from few pest problems, the exceptions being nematodes (Dirr, 1998) and spider mites (Gillman, 1998).

Garden use of Buddleja has been limited primarily to $B$. davidii Franch. However, there are some notable exceptions. 'Lochinch' is an offspring of hybridization between $B$. davidii and $B$. fallowiana Balf., and possesses the silvery-gray foliage of $B$. fallowiana, and the hardiness, habit and panicle size of $B$. davidii. 'Honeycomb' and 'Sungold', both hybrids of $B$. globosa Hope and B. davidii, have the yellow flower color of $B$. globosa and foliar character and plant habit intermediate between these two species (Dirr, 1998).

To date, hybridization of the Asian species $B$. davidii and $B$. lindleyana Fort. ex Lindl. has not been reported in literature. Buddleja lindleyana possesses characteristics that would be desirable to incorporate into $B$. davidii. It has evergreen to semi-evergreen foliage in zones 7 to 9 , produces purple-colored panicles that are considerably longer than B. davidii, and can be encouraged to grow on a trellis or to weave through the canopy of a tree, where its long drooping panicles can be displayed with maximal effectiveness. Also, $B$. lindleyana is considered to be more mite resistant

Received for publication 21 Jan. 2004. Accepted for publication 27 Mar. 2004. The authors appreciate the contributions of W.E. Kloos for generating thought; L. Snelling, for support of this project; J. Chaparro for conducting the RAPD reactions; and J. Dietz for statistical consultation.

${ }^{1}$ Graduate student.

${ }^{2}$ Professor.

HortScience Vol. 39(7) DeCEMber 2004
(Dirr, 1998). A successful interspecific hybrid of B. davidii var. nanhoensis (Chitt.) Rehd. 'Nanho Purple' and B. lindleyana has been made. The objectives of this work described herein are to verify the hybrid status of the seedling produced, characterize the floral and vegetative characters of the hybrid, and to validate a name for the hybrid taxon.

\section{Materials and Methods}

Numerous controlled crosses between $B$. davidii var. nanhoensis 'Nanho Purple' and $B$. lindleyana were made, resulting in a single hybrid seedling (herein referred to as the hybrid). 'Nanho Purple' was used as the female parent. This seedling was grown in the N.C. State University Horticultural Science greenhouse in Raleigh, and stem cuttings were made of this individual plant for further testing.

In Spring 2001, three vegetatively propagated specimens each of the hybrid, $B$. davidii 'Nanho Purple' and B. lindleyana were transplanted outdoors at the Horticultural Field Laboratory in Raleigh and grown under standard cultural conditions. Characterization of floral and vegetative characters of the hybrid and both Winter leaf defoliation was assessed visually in January 2003.

Color was assessed by observation using the Royal Horticultural Society Colour Chart (Royal Horticultural Society, 1986). Color designations (e.g., reddish-brown) represent the author's personal perceptions, while the color value designations (e.g., RHS 174A) refer to corresponding RHS color chips.

Self- and cross-fertility of the hybrid and both parents were assessed by making controlled self- and cross-pollinations in the greenhouse. Cross-pollinations were made using standard hybridization procedures. For each pollination, panicles containing flowers one to two days before anthesis were selected. The flowers were emasculated and fresh pollen of the male parent was applied with a camel's hair brush to the stigmatic surface of each flower immediately afteremasculation. Pollinations were performed over a four-month period of time, from July through November 2000. parents were made for two consecutive years.
11 inflorescences of the hybrid. In total, 774 flowers on 11 inflorescences of $B$. davidii 'Nanho Purple' were self-pollinated. Four panicles of B. lindleyana were self-pollinated, resulting in a total of 189 flowers.

Fertility of the hybrid relative to both parents was assessed by crossing all three taxa as male parents to $B$. fallowiana and to $B$. davidii cultivars 'White Ball', 'Black Knight', and 'Dartmoor', using the hybrid and both parents as the pollen source. Between 7 and 13 inflorescences were pollinated for each combination, with total flowers pollinated ranging from 430 to 1664 flowers per combination. Seed capsules were harvested at maturity, as defined by their dried appearance and the beginning of dehiscence. The seed capsules were placed in paper envelopes, dried for an additional 2 to 3 $\mathrm{d}$ at room temperature, and stored at $4{ }^{\circ} \mathrm{C}$ until they were sown. For germination, seeds were sown on sterile media (Fafard \# 4) and placed under intermittent mist. The number of germinated seedlings for each cross combination was counted after 3 to 5 weeks.

Pollen fertility of the hybrid and both parents was determined by culturing pollen obtained from newly opened flowers on germination media (Brewbaker and Kwack, 1963). A fine camel's hair brush was used to remove pollen from the anthers of several flowers representing several inflorescences of the same plant. Three petri dishes containing media were made for each taxa. Pollen was placed on the media and allowed to germinate for $3 \mathrm{~h}$. Pollen germination was measured by examining the pollen under $100 \times$ magnification. Germination was defined as the pollen tube being at least as long as the diameter of the pollen grain. This procedure was replicated three times over the course of 5 weeks. Pollen fertility of the hybrid and both parents was compared using a repeated measures ANOVA with data composed of arcsine transformation of the percent pollen germination.

Randomly amplified polymorphic DNA (RAPD) reactions were performed on leaf samples of the hybrid and each parent to confirm hybridity. RAPD primers OPAV11, OPW-16, OPX-18, OPAA-11,(AC)8CA, (AC)8CT, (AC)8TT and (AG)8CC were used in accordance with previously reported procedures (Chaparro et al., 1994).

Vouchers in flower of B. davidii 'Nanho Purple (6611 and 6613, NCSC; 6612, NA), B. lindleyana (6614 and 6616, NCSC; 6615, NA) and the hybrid (6617 and 6619, NCSC; 6618, NA) were collected by Fantz and Elliott. Vouchers sent to the United States National Arboretum(NA) included 6612, 6615, and 6618, and the remaining vouchers were deposited at the NCSU Herbarium (NCSC).

\section{Results and Discussion}

Morphological comparison of taxa. The hybrid resembles both parents in having angulate stems, opposite green leaves, purpleviolet corolla lobes, glabrous ovules, and four stamens. The inflorescence of each taxa is an indeterminate thyrse. Fruits are capsules. A summary of distinguishing characters compar- 
Table 1. A comparison of the hybrid characters with those of the parents Buddleja davidii 'Nanho Purple' and B. lindleyana.

\begin{tabular}{|c|c|c|c|}
\hline Characteristic & B. davidii 'Nanho Purple' & Hybrid & B. lindleyana \\
\hline \multicolumn{4}{|l|}{ Stems } \\
\hline \multirow[t]{2}{*}{ Color older stem } & $165 \mathrm{~A}-\mathrm{B}$ & $174 \mathrm{~A}, 175 \mathrm{~A}-\mathrm{B}$ & $172 \mathrm{~A}, 174 \mathrm{~A}$ \\
\hline & Dark brown & Reddish-brown & Reddish-brown \\
\hline Suckering & No & No & Yes \\
\hline \multicolumn{4}{|l|}{ Leaves } \\
\hline Petiole length (mm) & (0) $2-4$ & $0-3(5)$ & (2) $3-6(7)$ \\
\hline Length/width ratio & $3.1-5.6$ & $2.3-3.4$ & $1.4-2.2(2.6)$ \\
\hline Shape & Lanceolate, oblong, oblanceolate, linear & Lanceolate, oblong, elliptical & Ovate-lanceolate \\
\hline Margin & Serrate-crenate & Serrate & Entire (crenate) \\
\hline \multirow[t]{2}{*}{ Lower surface color } & 194A-195A-196A & 148C, 147B (194A) & $147 \mathrm{~A}, 147 \mathrm{~B}, 147 \mathrm{C}$ \\
\hline & Silver-white & Pale green & Pale green \\
\hline Lower surface pubescence & White tomentose & Pale tan on midrib of young leaves & Brown pubescence on young leaves \\
\hline Upper surface & Dull color & Dull color & Shiny \\
\hline Winter leaf defoliation & $80 \%$ & $15 \%$ & $25 \%$ \\
\hline \multicolumn{4}{|l|}{ Inflorescence } \\
\hline Rachis length (mm) & $63-110(125)$ & (5) $85-212(383)$ & (132) 185-400 (450) \\
\hline Grouping & $3,5,7$ & 3 & 3 \\
\hline \multicolumn{4}{|l|}{ Flowers } \\
\hline Flower length (mm) & $13.1-16.9(18.5)$ & $16.4-21.8$ & (13.6) $14.3-18.7$ \\
\hline Total number flowers & (39) 48-90 & (26) $53-133$ & $161-280$ \\
\hline Number open flowers & (34) $41-90$ & $3-27(34)$ & (1) $3-11$ \\
\hline Odor & Fragrant & Nonfragrant & Nonfragrant \\
\hline \multicolumn{4}{|l|}{ Calyx } \\
\hline Width (mm) & $0.9-1.6$ & $1.3-2.2$ & $1.8-2.3$ \\
\hline \multicolumn{4}{|l|}{ Corolla } \\
\hline \multirow[t]{2}{*}{ Shape } & Salverform & Salverform & Tubular \\
\hline & Straight & $\begin{array}{l}\text { Mostly straight, a few } \\
\text { curved }\end{array}$ & Curved \\
\hline Pubescence & Sparse & Dense & Dense \\
\hline Lobe/tube width & $4.1-7.6$ & $3.0-5.6$ & $1.6-2.8$ \\
\hline Color-tube & 80B-C & $88 \mathrm{D}$ & $84 \mathrm{C}, 85 \mathrm{~A}$ \\
\hline Tube width (mm) & $0.8-1.7$ & $0.9-2.6$ & $1.6-3.0$ \\
\hline Lobe width (mm) & (5.1) $5.5-8.4$ & (5.4) $6.1-9.1$ & $4.1-6.1$ \\
\hline \multirow[t]{2}{*}{ Color-throat } & $25 \mathrm{~A}$ (edge), 28A, 31A & $158 \mathrm{~A}, 20 \mathrm{C}$ & $84 \mathrm{C}, 85 \mathrm{C}$ \\
\hline & Orange-yellow & Creamy yellow & Purplish-white \\
\hline \multicolumn{4}{|l|}{ Stamen } \\
\hline Length (mm) & 12 & 12 & 7 \\
\hline \multirow[t]{2}{*}{ Anther color } & $162 \mathrm{~A}$ & $166 \mathrm{~A}$ & $164 \mathrm{~A}$ \\
\hline & Muddy yellow & Dark brown & Medium red-brown \\
\hline \multirow[t]{2}{*}{ Filament color } & $156 \mathrm{~B}$ & 166D,199B & Clear, match throat \\
\hline & Green-gray & Taupe & \\
\hline \multicolumn{4}{|l|}{ Seed capsules } \\
\hline Length (mm) & $6-12$ & $6-12$ & $4-6$ \\
\hline Width (mm) & (0.9) $1.3-2.1$ & $1.9-2.9(3.4)$ & $2.2-3.6$ \\
\hline Length/width & $4.6-8.3(10.8)$ & (2.8) 3.6-4.7 (5.3) & $1.1-2.4$ \\
\hline
\end{tabular}

ing the hybrid and both parents is presented in juvenile leaves, with less obvious brown pu(Table 1).

The hybrid resembles $B$. davidii 'Nanho Purple' in several ways. The leaves have a similar shape, lanceolate to oblong-elliptical, with serrated edges and dull color. Petioles are rather short. Also, flowers of the hybrid resemble B. davidii in shape, in broad lobe width, and stamen length. Seed capsules are similar in length. There is no evidence of suckering in either the hybrid or 'Nanho Purple'.

The hybrid resembles $B$. lindleyanain several ways. The color of the older stems is similar. The underside of the leaf is similar in pubescence and is almost concolorous. There is very little winter leaf defoliation. Flowers are similar to $B$. lindleyana in that they are grouped in sets of three, lack fragrance, have broader calyxes, and the outer corolla tube is densely pubescent and sparkles when the light hits the hairs.

Thehybrid displays characteristicsintermediate between the two parents. The length to width ratios of the leaves and of the seed capsule are intermediate. The leaf undersides of $B$. davidii are tomentose, even canescent. The leaf undersides of $B$. lindleyana have brown pubescence bescence limited to the veins on mature leaves. The undersides of the leaves of the hybrid are tomentulose on juvenile leaves, and have pale tan pubescence on the midrib. The panicles of $B$. lindleyana are elongate and arch downward, with flowers occurring in sets of three, with only a few (3 to 11) flowers in the panicle open at one time. The inflorescence of 'NanhoPurple' is more compact, with denser sets of flowers (sets of 3,5, or 7) and flowers generally blooming simultaneously (41 to 90). The inflorescence of the hybrid is intermediate in length, with 3 to 27 flowers open at one time (Fig. 1). The individual corolla tube length of the hybrid flower is greater than either parent. The ratio of the width of the corolla lobe to the width of the tube is intermediate. The color of the hybrid's throat is a creamy yellow, whereas the throat of $B$. lindleyana is the same pale purple color of the tube, and the throat of $B$. davidii has an orange-yellow eye.

Fertility. The hybrid is fertile as a male parent, generally similar to $B$. davidii 'Nanho Purple', based on the number of viable seed produced per pollinated flower on selected cultivars of $B$. davidii female parents. Both the hybrid and $B$. lindleyana produced viable seed after self-pollination, unlike B. davidii 'Nanho Purple' which lacked self-seed production. Crosses between the hybrid and $B$. fallowiana were more successful than crosses of $B$. fallowiana with either parent (Table 2). Pollen viability of the hybrid is similar to that of $B$. lindleyana (Table 3). Field observations reveal considerable hybrid seed set, suggesting high female fertility as well.

Analysis of the RAPD reactions confirms hybrid origin. RAPD primers OPAV-11, OPW16, and OPX-18 amplified clear, reproducible bands that show hybrid origin (Fig. 2). Buddleja lindleyana is a diploid species, possessing 38 chromosomes whereas $B$. davidii is a tetraploid species with 76 chromosomes (Moore, 1947). A successful hybridization between these two species might be expected to result in a triploid hybrid, unless $B$. lindleyana produces unreduced $(2 \mathrm{x})$ gametes, resulting in a tetraploid. The fertility of the hybrid suggests that it is a tetraploid, and suggests that $B$. lindleyana produces unreduced gametes.

Culture. The hybrid is easy to root from softwood and semi-hardwood stem cuttings. Flowers are formed on new growth, thus prun- 


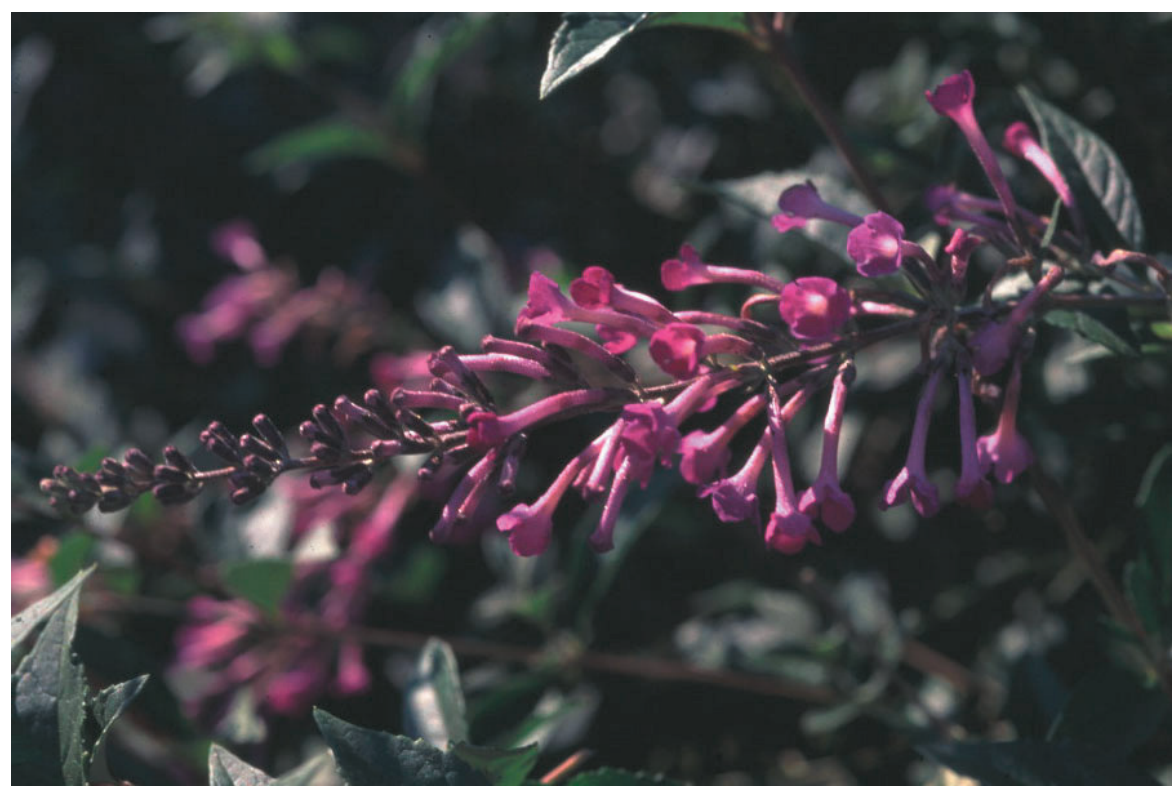

Fig. 1. Inflorescence of Buddleja davidii x B. lindleyana hybrid.

ing before spring growth is recommended. The hybrid seems to grow best under cooler temperatures, as compared to B. davidii, and extends the flowering season into fall. It appears to be more shade tolerant than many Buddleja.

Availability. Currently, the hybrid is not in general commerce. Propagules can be obtained from Dennis Werner, Department of Horticulture, N.C. State University, Raleigh.

\section{Conclusion}

The hybrid exhibits characteristics of both parents, as well as a number of intermediate traits. Flowers tend to be larger than either parent with an extended blooming period. The hybrid grows better in cooler temperatures, loses fewer leaves in winter, and is more floriferous. Therefore, it will be a useful addition for landscape plantings. The hybrid is successful in producing viable seed from controlled crosses with other Buddleja species, in contrast with limited fertility of $B$. lindleyana in such cases. The hybrid can provide stock material for introducing desirable characteristics of the diploid

B. lindleyana for cultivar improvement in the tetraploid B. davidii.

Hybrid nomenclature and morphology. Buddleja luteolufaucia Elliott and Fantz $\{$ Buddleja davidii var. nanhoensis (Chitt.) Rehd. X Buddleja lindleyana Fort. ex Lindl.\} distingibili inflorescentia thryso laxo; floribus ternatis, purpureis, nonodoriferis; corolla tubo elongato, pubencenti denso et lucenti, cum fauce flavo cremeo.

Shrub, low mounding, currently to $1.1 \mathrm{~m}$ tall $\times$ $2 \mathrm{~m}$ wide. Stems angulate, slightly winged; older stems reddish-brown (174A, 175 A-B). Leaves are opposite, lanceolate, acute to acuminate, cuneate to attenuate, serrate, dull green above (147A) and paler green below (147B, 148C), 32 to $83 \mathrm{~mm}$ long and 10 to $30 \mathrm{~mm}$ wide; pale tan pubescence on lower surface ribs of young leaves; petiole 0 to $3 \mathrm{~mm}$. Inflorescence is an indeterminate thyrse with flowers in groups of 3 ; rachis to $383 \mathrm{~mm}$ long. Flowers are odorless, salverform; calyx 3.1 to $5.8 \mathrm{~mm}$ long, 1.3 to $2.2 \mathrm{~mm}$ wide with fine hairs; corolla densely pubescent and glistening, soft bluish-violet (80 to $81 \mathrm{~A}, 82 \mathrm{~A}, 87 \mathrm{~B})$ with throat creamy yellow (158A, 20C), 16 to $22 \mathrm{~mm}$ long, lobes 6 to 9

Table 2. Male fertility of a Buddleja davidii 'Nanho Purple' x B. lindleyana hybrid and both parents as measured by the average number of viable seeds produced per pollinated flower after controlled hybridization of each to three cultivars of B. davidii ('White Ball', 'Black Knight', and 'Dartmoor') and to B. fallowiana 'Alba'.

\begin{tabular}{lcccc}
\hline Male & \multicolumn{4}{c}{ Female parent } \\
\cline { 2 - 5 } parent & White Ball & Black Knight & Dartmoor & B. fallowiana \\
\hline B. davidii 'Nanho Purple' & 0.43 & 6.69 & 2.49 & 1.18 \\
Hybrid & 0.58 & 4.57 & 3.43 & 2.36 \\
B. lindleyana & 0.0016 & 0.0027 & 0.0031 & 0.0054 \\
\hline
\end{tabular}

${ }^{2} \mathrm{~F}_{1}$ hybrid of B. davidii var. nanhoensis 'Nanho Purple' $\mathrm{x}$ B. lindleyana.

Table 3. Pollen viability of the hybrid and both parents as determined by in vitro pollen germination. ${ }^{2}$

\begin{tabular}{lcccr}
\hline & \multicolumn{4}{c}{ Percent germination } \\
\cline { 2 - 5 } Taxa & Time 1 & Time 2 & Time 3 & Mean $^{y}$ \\
\hline B. davidii 'Nanho Purple' & 5 & 6 & 1 & 4 a \\
Hybrid & 35 & 44 & 10 & 25 b \\
B. lindleyana & $\mathbf{2 3}$ & $\mathbf{6 3}$ & $\mathbf{1 6}$ & $\mathbf{3 7} \mathbf{~ b}$
\end{tabular}

${ }^{2}$ Viability determined as percentage germination after $3 \mathrm{~h}$ of incubation on Brewbaker and Kwack (1963) media.

${ }^{y}$ Means followed by different letters are significantly different at $P=0.05$ (LSD test)

${ }^{\mathrm{x}} \mathrm{F}_{1}$ hybrid of Buddleja davidii 'Nanho Purple' $\mathrm{x}$ B. lindleyana.

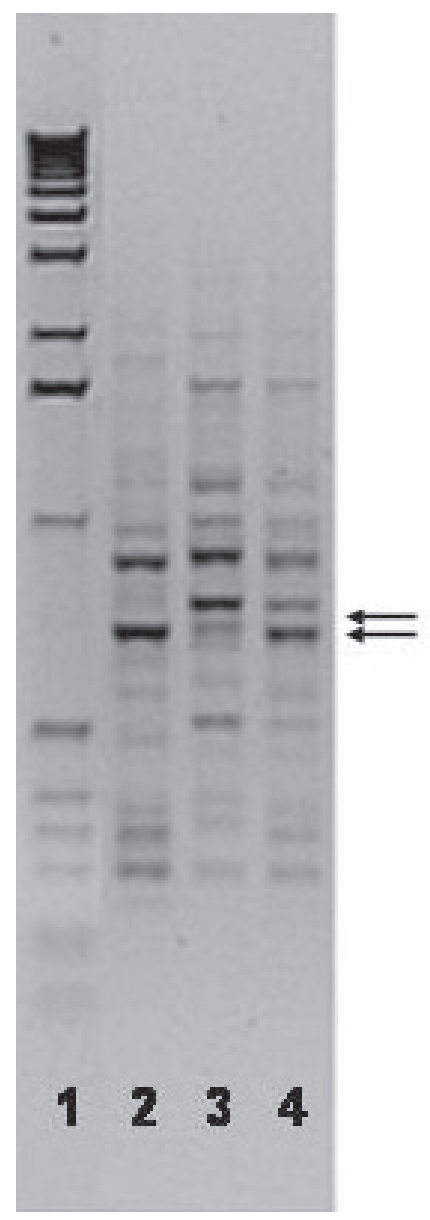

Fig. 2. RAPD banding patterns of Buddleja davidii (lane 2), B. lindleyana (lane 3), and the B. davidii $\mathrm{x}$ B.lindleyana hybrid (lane 4) using primer OPAV011. Lane $1=1 \mathrm{~kb}$ molecular marker. Top arrow shows a $0.8 \mathrm{~kb}$ band found in only $\mathrm{B}$. lindleyana and the hybrid. The bottom band shows a $0.74 \mathrm{~kb}$ band found only in B. davidii and the hybrid.

$\mathrm{mm}$ wide; stamens four, $12 \mathrm{~mm}$ long; ovary glabrous. Seed capsule 8 to $12 \mathrm{~mm}$ long, 1.9 to $3.4 \mathrm{~mm}$ wide. Holotype: Fantz and Elliott 6617 (NCSC); Paratypes: Fantz and Elliott 6618(NA) and 6619 (NCSC).

\section{Literature Cited}

Bhattacharyya, B. and B.M. Johri. 1998. Flowering plants: taxonomy and phylogeny. Narosa Publ. House, New Dehli.

Brewbaker, J.L. and B.H. Kwack. 1963. The essential role of calcium ion in pollen germination and pollen tube growth. Amer. J. Bot. 50:859-865.

Chaparro, J.X., D.J. Werner, D.O. Malley, R.R. Sederoff. 1994. Targeted mapping and linkage analysis of morphological, isozyme, and RAPD markers in peach. Theor Appl. Genet. 87:805-815.

Dirr, M.E. 1998. Manual of woody landscape plants: Their identification, ornamental characteristics, culture, propagation and uses. $5^{\text {th }}$ ed. Stipes Publ. Co., Champropagation

Gillman, J.H. 1998. Resistance of Buddleia L. taxa to the two-spotted spider mite. (Tetranychus uriticaeKoch). $\mathrm{PhD}$ diss. Univ. Ga., Athens.

Griffiths, M. 1994. The new Royal Hortcultural Society index of garden plants. Macmillan, London.

Moore, R.J. 1947. Cytotaxonomic studies in the Loganiaceae. I. Chromosome numbers and phylogeny in the Loganiaceae. Amer. J. Bot. 34:527-538.

Rogers, G.K. 1986. The genera of Loganiaceae in the southeastern United States. J. Arnold Arbor. 67:143-185.

Royal Horticultural Society. 1986. Royal Horticultural Society colour chart. Royal Hort. Soc., London. 